\title{
RANCANGBANGUN GAME EDUKASI PENGENALAN HURUF HIJAIYAH \\ DENGAN GAME EGINE CONSTRUCT 2
}

\author{
Sugeng Supriyadi ${ }^{1}$ \\ 1), Teknik Informatika Universitas Kuningan \\ Jl Cut Nyak Dien No 36 A Cijoho Kabupaten Kuningan \\ Email : sugeng@uniku.ac.id ${ }^{1)}$
}

\begin{abstract}
Abstrak
Game edukasi merupakan sebuah permainan dibuat dan dirancang khusus untuk dijadikan sebuah media yang digunakan untuk mengajar orang melalui materi yang berisikan suara, teks, gambar, video, dan animasi, yang pokok materinya membahas suatu subjek tertentu, yang memiliki tujuan untuk dapat memperluas konsep, memberikan pemahaman yang lebih baik dari materi yang mengajarkan sebuah peristiwa sejarah maupun budaya. Huruf hijaiyah adalah Dalam Kamus Besar Bahasa Indonesia kata hijaiyah berarti "system aksara Arab; Abjad Arab”. (Departemen Pendidikan Nasional, Op. Cit., hlm. 401). Agar bisa membaca AlQur'an, kita perlu mengenali huruf-huruf hijaiyah, bagaimana bentuknya dan cara membacanya. penulis merasa tertarik untuk meneliti dengan menerapkan pola Game Edukasi dengan pembelajaran huruf hijaiyah. Sehingga dalam proses belajar mengenal huruf hijaiyah tidak merasa jenuh dan semakin tertarik dan tahu bagaimana melafad kannya dengan baik dan benar. peneliti merancang sebuah game edukasi pengenalan huruf hijaiyah dengan judul "Rancangbangun Game Edukasi Pengenalan Huruf Hijaiyah Dengan Game Egine Construct 2.
\end{abstract}

Kata Kunci : Game Edukasi, Huruf Hijaiyah, Construct2.

Abstract

The educational game is a game created and designed specifically to serve as a medium used to teach people through materials that contain sound, text, images, video, and animation, whose subject covers a particular subject, which aims to expand the concept, a better understanding of the material that teaches a historical and cultural event. The hijaiyah letters are In Big Indonesian Dictionary the word hijaiyah means "the Arabic script system; Arabic alphabet ". (Ministry of National Education, Op. Cit., Pp. 401). In order to read the Qur'an, we need to recognize the letters hijaiyah, how to shape and how to read it. the authors feel interested to research by applying the pattern of Educational Game with learning hijaiyah letters. So in the process of learning to know the letters hijaiyah not feel saturated and more interested and know how to melafad kannya well and correctly. researchers designed an educational game introducing hijaiyah letters with the title "Design Game Education Introduction Hijaiyah Letter With Egine Construct Game 2

Keywords: Game Education, Hijaiyah Letters, Construct2.

\section{PENDAHULUAN}

Game edukasi merupakan sebuah permainan dibuat dan dirancang khusus untuk dijadikan sebuah media yang digunakan untuk mengajar orang melalui materi yang berisikan suara, teks, gambar, video, dan animasi, yang pokok materinya membahas suatu subjek tertentu, yang memiliki tujuan untuk dapat memperluas konsep, memberikan pemahaman yang lebih baik dari materi yang mengajarkan sebuah peristiwa sejarah maupun budaya.

Huruf hijaiyah adalah Dalam Kamus Besar Bahasa Indonesia kata hijaiyah berarti "system aksara Arab; Abjad Arab". (Departemen Pendidikan Nasional, Op. Cit., hlm. 401).
Huruf hijaiyah sangatlah berperan penting bagi umat islam, karena untuk beribadah umat islam harus bias membaca Al-qur'an. Kunci untuk membaca Al-qur'an adalah dengan mengenal dan bisa melafadkan huruf hijaiyah. Al-Qur'an menggunakan bahasa Arab dan huruf hijaiyah. Meski begitu, Al-Qur'an diturunkan bukan cuma untuk orang Arab saja, tetapi seluruh umat Islam di dunia. Untuk itu, agar bisa memahami isi bacaan Al-Qur'an. Huruf hijaiyah bukan huruf yang utama digunakan sehari-hari. Di sekolah reguler ataupun yang diajarkan adalah cara membaca huruf latin. Namun, untuk belajar membaca huruf Arab, kini sudah banyak sekolah madrasah atau guru ngaji yang mau mengajarkannya

Agar bisa membaca Al-Qur'an, kita perlu mengenali huruf-huruf hijaiyah, bagaimana 
bentuknya dan cara membacanya. penulis merasa tertarik untuk meneliti dengan menerapkan pola Game Edukasi dengan pembelajaran huruf hijaiyah. Sehingga dalam proses belajar mengenal huruf hijaiyah tidak merasa jenuh dan semakin tertarik dan tahu bagaimana melafad kannya dengan baik dan benar. peneliti merancang sebuah game edukasi pengenalan huruf hijaiyah dengan judul "Rancangbangun Game Edukasi Pengenalan Huruf Hijaiyah Dengan Game Egine Construct 2

Rumusan permasalahan dalam penelitian ini:

1. Bagaimana membuat game edukasi pengenalan huruf hijaiyah yang menerapkan audio dan text yang menjelaskan pengucapat lafad yang baik dan bernar.?

2. Bagaimana merancang dan membangun game edukasi dengan game egine construct 2 ?

3. Bagaimana merancang interface game edukasi yang user friendly?

Batasan Masalah dalam penelitian ini yaitu:

1. Perancangan aplikasi di buat dengan metodologi pengembangan sistem $S D L C$.

2. Games edukasi yang akan dibangun mennggunakan game egine construct 2 .

3. Menu dari game edukasi mencakup pengenalan huruf hijaiyah image, audio, dan text.

Maksud dan Tujuan dari penelitian ini adalah sebagai berikut :

Maksud dari penelitian ini adalah sebagai berikut:

1. Sebagai sarana edukasi pengenalan huruf hijaiyah.

2. Sebagai pembelajaran yang interaktif untuk mengenal huruf dan pengucapan hijaiyah.

Adapun Tujuan dari penelitian ini adalah sebagai berikut:

1. Mempermudah user dalam mempelajari huruf hijaiyah

2. Mempermudah pengenalan huruf dan pembacaan huruf hijaiyah yang baik dan benar.

3. Sebagai sarana edukasi yang interaktif dan menyenangkan.

\section{Definisi Games}

Permainan (games) adalah setiap kontes antara pemain yang berinteraksi satu sama lain dengan mengikuti aturan-aturan tertentu untuk mencapai tujuan tertentu pula (Sadiman, 1993:75).

Game berasal dari kata bahasa inggris yang berarti dasar permainan. Permainan dalam hal ini merujuk pada pengertian kelincahan intelektual( Intellectual Playability Game) yang juga bisa diartikan sebagai arena keputusan dan aksi pemainnya. Dalam game, ada target-target yang ingin dicapai pemainnya.
Menurut Wahono (ilmukomputer.com.2007) mengemukakan game merupakan aktifitas terstruktur atau semi terstruktur yang biasanya bertujuan untuk hiburan dan kadang dapat digunakan sebagai sarana pendidikan

\section{Pengertian Huruf Hijaiyah}

Dalam Kamus Besar Bahasa Indonesia kata hijaiyah berarti "system aksara Arab; Abjad Arab". (Departemen Pendidikan Nasional, Op. Cit., hlm. 401)

Kata huruf berasal dari bahasa arab harf atau huruuf(حرف او حروف). Huruf arab disebut juga huruf hija'iyah (هجائية). Kata hija'iyah berasal dari kata kerja hajjaa (هجى)yang artinya mengeja, menghitung huruf, membaca huruf demi huruf. Huruf hija'iyah disebut pula huruuf tahjiyyah (حروف تهجية) (Muhyiddin, Sekilas Sejarah Tulisan Bahasa Arab, Semprulle, Kediri, 2012, hlm. 3).

Huruf hijaiyah disebut juga alfabet arab. Kata alfabet itu sendiri berasal dari bahasa arab alif, $b a$ ', ta'. (Abd. Karim Husain, Seni Kaligrafi Khat Naskhi,Tuntunan Menulis Halus Huruf Arab Dengan Metode Komparatif(Jakarta: Pedoman Ilmu Jaya, 1988), hlm. 5)

\section{Game Egine Construct 2}

Construct 2 adalah game egine yang dapat digunakan untuk membuat game. Construct mendukung untuk membuat game android, Web (HTML5), Wii U, iOS, Windows 8, dan sebagainya.

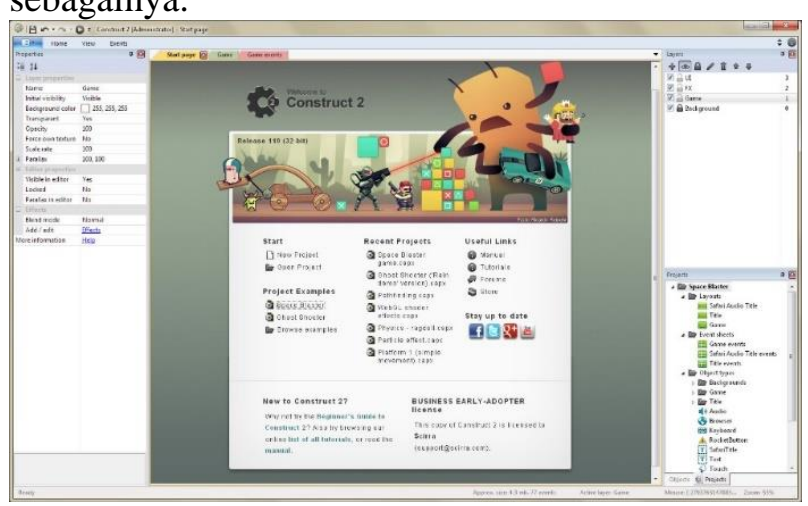

Gambar 1. Game Egine Construct 2

\section{METODE PENELITIAN}

Metodologi Berorientasi Objek

Objek juga didefinisikan sebagai berikut:

"objek dapat didefinisikan sebagai suatu encapsulation atau penggabungan dari data (yang diwakilkan oleh atribut-atribut) dan operasioperasi (disebut juga metode/prosedur) yang akan melakukan proses terhadap data-data tersebut."

Keuntungan Metodologi Berorientasi Objek 
Keunggulan metoda berarah objek diantaranya adalah (Coad and Yourdon, 1991):

1. Meningkatkan produktifitas

Karena kelas dan objek yang ditemukan pada suatu kasus masih dapat dipakai ulang untuk kasus lainnya yang melibatkan objek tersebut(reusable);

2. Meningkatkan kualitas

Karena sistem yang dibangun dengan baik dan benar pada saat analisis dan perancangannya akan menyebabkan kekurangannya kesalahan pada saat pengkodean,

3. Mempermudah perawatan

Karena dengan model objek pola-pola yang cenderung tetap dan stabil dapat dipisahkan dari pola-pola yang mungkin sering berubah-ubah,

4. Adanya konsistensi

Karena sifat pewarisan dan penggunaan notasi yang sama pada saat analisis, perancangan, maupun pengkodean.

\section{Unified Modelling Language (UML)}

Unified Modelling Language (UML) adalah keluarga notasi grafis yang didukung oleh modelmodel tunggal, yang membantu pendeskripsian dan desain sistem perangkat lunak, khususnya sistem yang dibangun menggunakan pemrograman berorientasi objek.(Martin Fowler,2004).

Dengan menggunakan $U M L$ kita dapat membuat model untuk semua jenis aplikasi piranti lunak, dimana aplikasi tersebut dapat berjalan pada piranti keras, sistem operasi dan jaringan apapun, serta ditulis dalam bahasa pemrograman apapun. Tetapi karena UML juga menggunakan class dan operation dalam konsep dasarnya, maka ia lebih cocok untuk penulisan piranti lunak dalam bahasabahasa berorientasi objek seperti C++, Java, C\# atau VB.NET. Walaupun demikian, $U M L$ tetap dapat digunakan untuk modeling aplikasi prosedural dalam VB atau C.

\section{Metode Pengembangan Sistem SDLC}

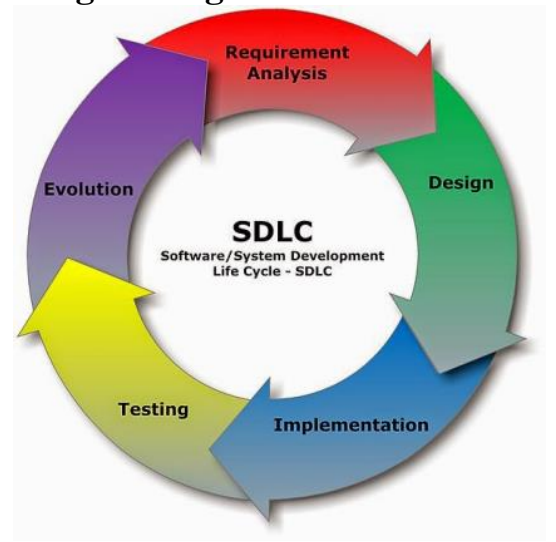

Gambar 2. Model SDLC
Kegiatan yg menyangkut estimasi dr kebutuhankebutuhan fisik, tenaga kerja \&dana yang dibutuhkan untuk mendukung pengembangan sistem serta untuk mendukung operasinya setelah diterapkan.

2. Analysis

Dalam tahap analisis ini, digunakan oleh analis sistem untuk :

a. Membuat keputusan apabila sistem saat ini mempunyai masalah atau sudah tidak berfungsi secara baik dan hasil analisisnya digunakan sebagai dasar untuk memperbaiki sistem

b. Mengetahui ruang lingkup pekerjaannya yang akan ditanganinya.

c. Memahami sistem yang sedang berjalan saat ini

d. Mengidentifikasi masalah dan mencari solusinya

3. Design

Mendesain sistem baru yang dapat menyelesaikan masalah-masalah yang dihadapi perusahaan yang diperoleh dari pemilihan alternatif sistem yang terbaik

4. Development

Merupakan tahap penulisan program yang telah dianalisis dan desain.Membuat Technical Architecture, create database. Mengkonversikan perancangan logikal ke dalam kegiatan operasi coding dengan menggunakan bahasa pemograman tertentu

5. Testing

Dalam tahap ini tidak hanya menguji desain yang digunakan namun menguji semua sistem yang telah ditetapkan, seperti tidak ada kesalahan, image yang salah, pengujian sistem seperti penyimpanan data dan lain-lain.

6. Implementation

Dalam tahap implementasi memiliki beberapa tujuan, yaitu untuk

a. Melakukan kegiatan spesifikasi rancangan logikal ke dalam kegiatan yang sebenarnya dari sistem informasi yang akan dibangunnya atau dikembangkannya.

b. Mengimplementasikan sistem yang baru.

c. Menjamin bahwa sistem yang baru dapat berjalan secara optimal.

7. Maintenance

Tahap akhir untuk mengevaluasi kinerja sistem, apakah sesuai dengan keinginan user atau tidak.

\section{HASIL DAN PEMBAHASAN}

\section{Perancangan Use Case Diagram}

Use Case Diagram mendeskripsikan sistem/aplikasi, lingkungan dan relasi antara 
sistem/aplikasi dengan lingkungannya. Dalam aplikasi yang dibuat, user memiliki beberapa perlakuan umum yang dapat dilakukan.

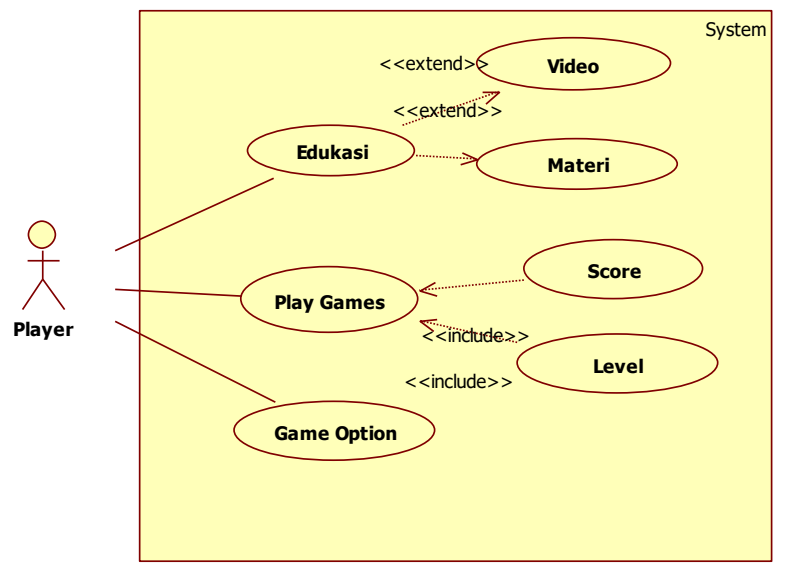

Gambar 3 Use case diagram

\section{Skenario Use Case Play Game}

Tabel 1. Skenario Use Case Play Game

\begin{tabular}{|c|c|c|}
\hline $\begin{array}{l}\text { Nama } \\
\text { Use Case }\end{array}$ & \multicolumn{2}{|l|}{ Play Game } \\
\hline Aktor & \multicolumn{2}{|l|}{ Player } \\
\hline Deskripsi & \multicolumn{2}{|c|}{$\begin{array}{l}\text { Proses Ini adalah sebuah kegiatan } \\
\text { untuk memainkan game. }\end{array}$} \\
\hline \multirow{2}{*}{$\begin{array}{l}\text { Kondisi } \\
\text { Normal }\end{array}$} & Player & Reaksi Game \\
\hline & $\begin{array}{l}\text { 1.Memilih menu } \\
\text { Play. } \\
\text { 2. Memilih Level } \\
\text { 3. Melihat Score }\end{array}$ & $\begin{array}{l}\text { 1. Mengecek } \\
\text { player dan } \\
\text { level. } \\
\text { 2. Menampilkan } \\
\text { Menu Level. } \\
\text { 3. Menampilkan } \\
\text { Permainan } \\
\text { sesuai level } \\
\text { dan Score } \\
\end{array}$ \\
\hline \multirow{2}{*}{$\begin{array}{l}\text { Kondisi } \\
\text { Alternatif }\end{array}$} & Player & Reaksi Game \\
\hline & $\begin{array}{l}\text { 1.Memilih menu } \\
\text { Play. } \\
\text { 2. Memilih Level } \\
\text { 3. Melihat Score }\end{array}$ & $\begin{array}{l}\text { 1. Level tercapai } \\
\text { 2. Unlock level } \\
\text { 3. High Score }\end{array}$ \\
\hline $\begin{array}{l}\text { Pre- } \\
\text { Condition }\end{array}$ & \multicolumn{2}{|c|}{ Player Memainkan Permainan } \\
\hline $\begin{array}{l}\text { Post- } \\
\text { Condition }\end{array}$ & $\begin{array}{l}\text { Player Memilih } \\
\text { bermain }\end{array}$ & Level sebelum \\
\hline
\end{tabular}

\section{Perancangan Activity Diagram}

Activity Diagram merupakan gambaran aliran kejadian suatu aplikasi. Pada activity diagram ini menggambarkan proses yang berjalan di sistem yang dilakukan oleh pengguna dari awal membuka aplikasi sampai menutup aplikasi. Berikut ini adalah gambaran activity diagram:

\section{Activity diagram Game Option}

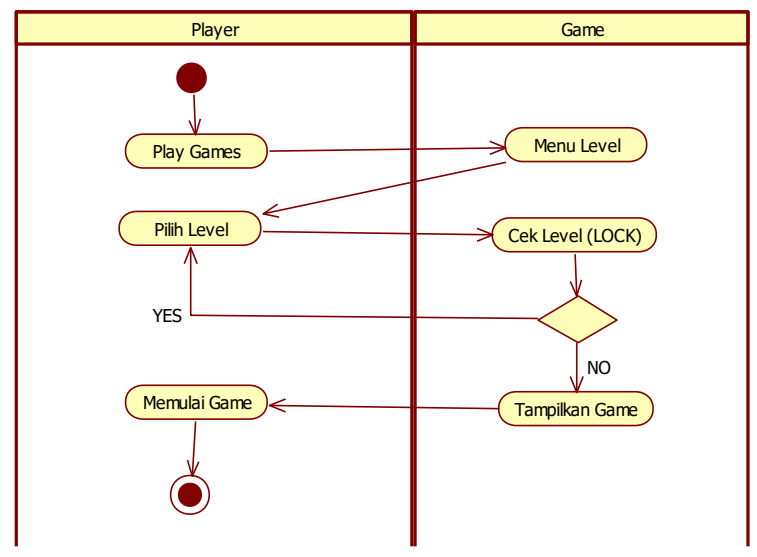

Gambar 4. Activity diagram Game Option Dari activity diagram diatas, maka identifikasi proses yang terjadi diuraikan pada table berikut:

Tabel 2. Deskripsi activity diagram game option

\begin{tabular}{|c|l|l|}
\hline No & Swimline & \multicolumn{1}{|c|}{ Identifikasi Proses } \\
\hline 1 & Player & $\begin{array}{l}\text { 1. Pilih Play Game } \\
\text { 2. Pilih Level } \\
\text { 3. Memainkan Game }\end{array}$ \\
\hline 2 & Game & $\begin{array}{l}\text { 1. Menampilkan menu Level } \\
\text { 2. Cek Level } \\
\text { 3. Tampilkan Permainan }\end{array}$ \\
\hline
\end{tabular}

\section{Perancangan Class Diagram}

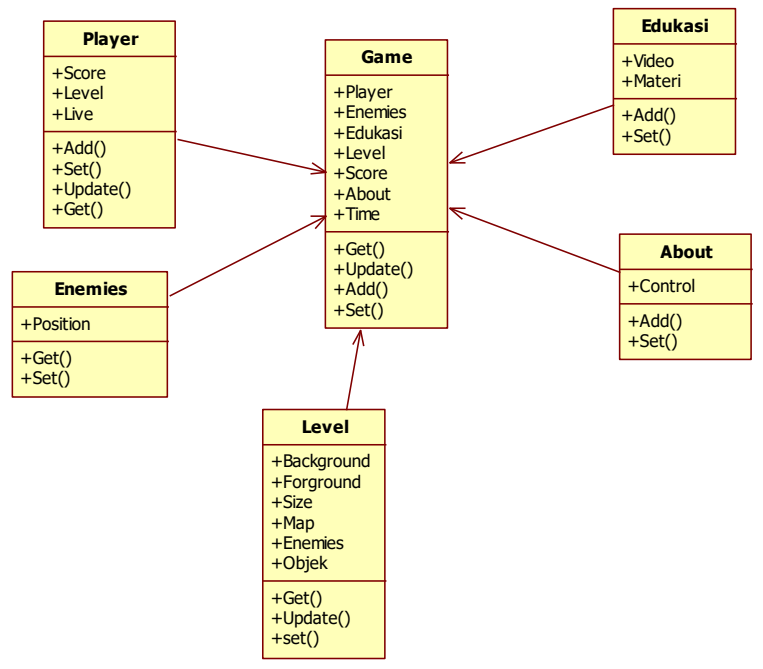

Gambar 5. Class diagram

\section{Implementation}

Layout utama ini adalah tampilan ketika game dijalankan, sehingga player dapat memilih menu yang terdapat pada game tersebut. Dapat dilihat seperti gambar 6 dibawah ini : 


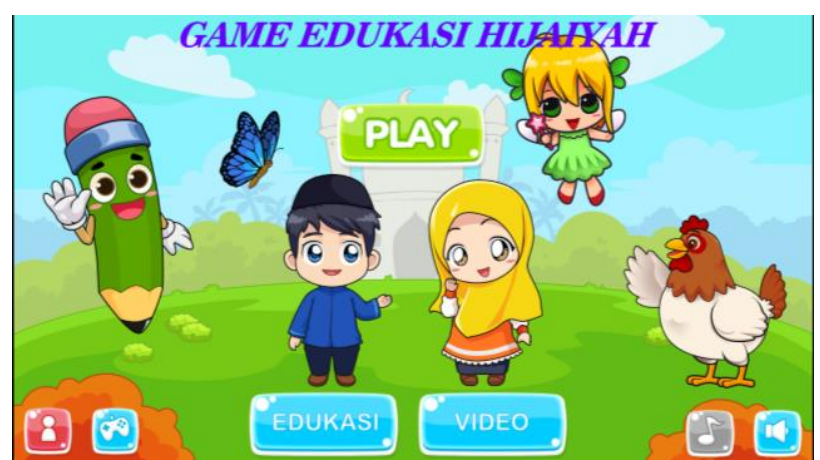

Gambar 6. Layout Utama Game

\section{Layout Level}

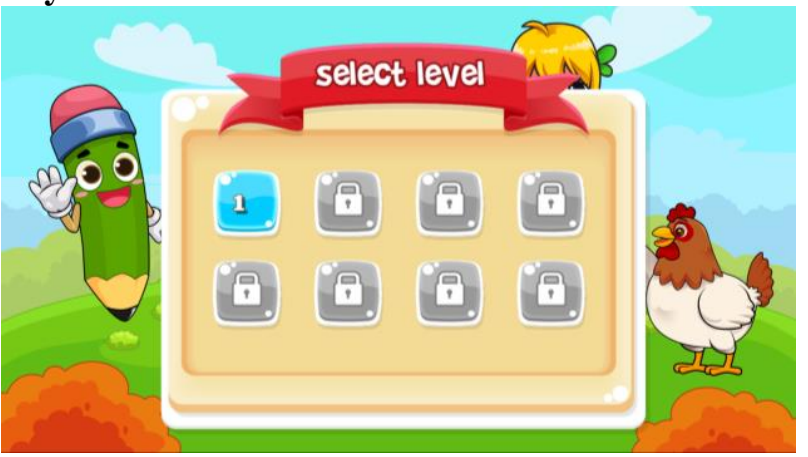

Gambar 7. Layout Level

Layout ini akan tampil ketika player memilih menu play game pada layout utama. Layout level ini menampilkan level yang ada pada game tersebut, sehingga player dapat dengan mudah mengakses level yang diinginkan. Level game yang tidak aktif akan aktif ketika player menyelesaikan level demi level dari bawah

\section{Layout Level Permainan}

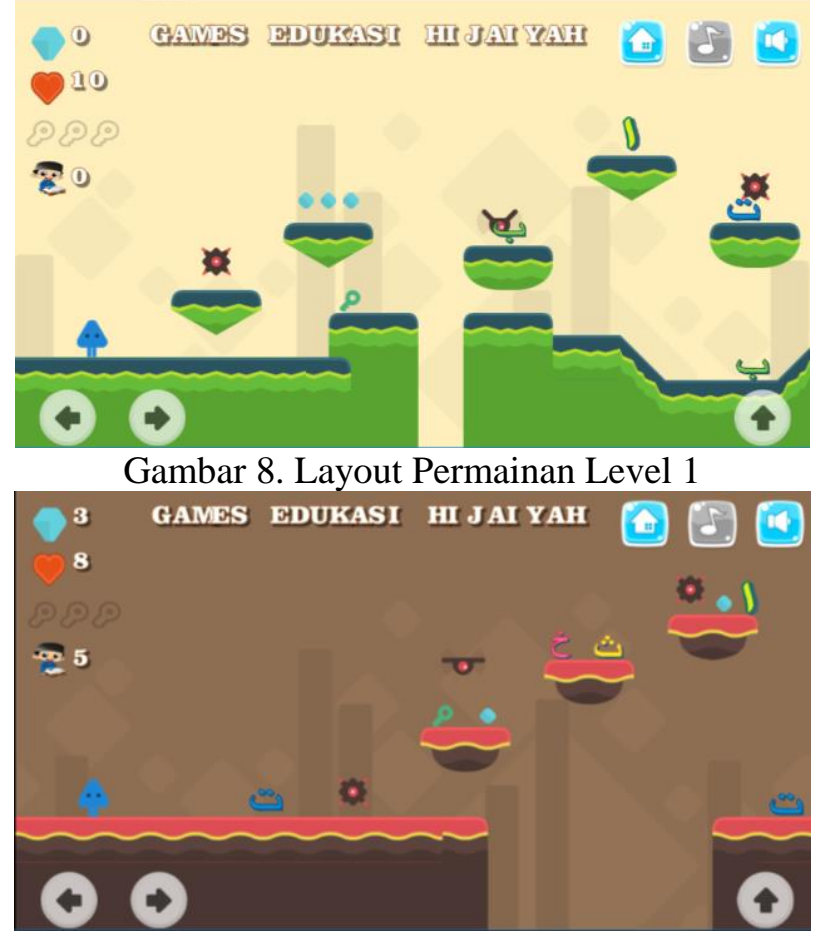

Gambar 9. Layout Permainan Level 2

Layot ini adalah permainan dari game hijaiyah.
Terdapat beberapa komponen di dalam layout ini, yaitu :

a. Backgroud game

b. Player

c. Enemies

d. HUD/permata

e. Heart/Live Player

f. Mengaji

g. Huruf Hijaiyah

h. Key/Kunci untuk membuka ke level selanjutnya

\section{Layout Edukasi}

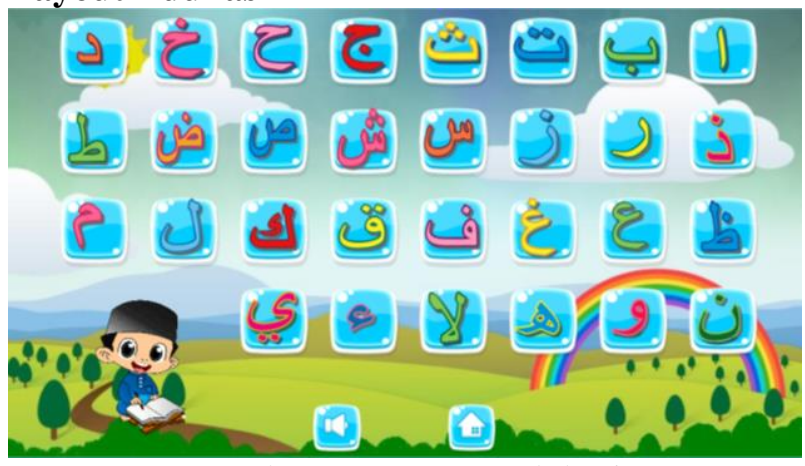

Gambar 10. Layout Edukasi

Layout ini adalah layout utama untuk pembelajaran hijaiyah. Pada layout ini player berinteraksi dengan menklik/menyentuh huruf hijaiyah dan game akan merespon dengan suara huruf hijaiyah tersebut.

\section{Testing}

Pengujian black box adalah proses pengujian aspek fundamental aplikasi tanpa memperhatikan struktur logika internal perangkat lunak. Proses pengujian ini dilakukan untuk mengetahui apakah aplikasi perangkat lunak dapat berjalan dan berfungsi dengan benar.

\section{Pengujian Black Box}

Adapun hasil pengujian black box yang telah dilakukan pada Form Menu dapat dilihat pada Tabel dibawah ini :

Tabel 3..Hasil Pengujian Black Box

\begin{tabular}{|c|c|l|l|l|}
\hline No & $\begin{array}{c}\text { Fungsi } \\
\text { yang di } \\
\text { uji }\end{array}$ & $\begin{array}{l}\text { Cara } \\
\text { Menguji }\end{array}$ & $\begin{array}{l}\text { Hasil yang } \\
\text { diharapkan }\end{array}$ & $\begin{array}{l}\text { Hasil } \\
\text { yang } \\
\text { keluar }\end{array}$ \\
\hline 1 & $\begin{array}{l}\text { Tombol } \\
\text { Control }\end{array}$ & $\begin{array}{l}\text { Player } \\
\text { melakukan } \\
\text { control ke } \\
\text { Objek } \\
\text { Player }\end{array}$ & $\begin{array}{l}\text { Player } \\
\text { bergerak } \\
\text { sesuai } \\
\text { control }\end{array}$ & $\begin{array}{l}\text { Sesuai } \\
\text { dengan } \\
\text { harapan } \\
\text { Valid }\end{array}$ \\
\hline 2 & $\begin{array}{l}\text { Tombol } \\
\text { Hijaiyah } \\
\text { Edukasi }\end{array}$ & $\begin{array}{l}\text { Player } \\
\text { melakukan } \\
\text { klik/touch } \\
\text { ke objek } \\
\text { button } \\
\text { edukasi }\end{array}$ & $\begin{array}{l}\text { Keluar } \\
\text { audio } \\
\text { sesuai } \\
\text { dengan } \\
\text { huruf yang } \\
\text { di } \\
\text { klik/touch }\end{array}$ & $\begin{array}{l}\text { Sesuai } \\
\text { dengan } \\
\text { harapan } \\
\text { Valid }\end{array}$ \\
\hline 3. & Edukasi & Player & Layout & Sesuai \\
\hline
\end{tabular}




\begin{tabular}{|l|l|l|l|l|}
\hline Video & memilih & video & dengan \\
& $\begin{array}{l}\text { menu } \\
\text { video } \\
\text { edukasi dan }\end{array}$ & $\begin{array}{l}\text { video } \\
\text { harapan } \\
\text { ealid }\end{array}$ \\
& muncul & \\
\hline
\end{tabular}

\section{KESIMPULAN}

Game edukasi yang telah dibuat dengan judul

Rancang Bangun Game Edukasi Pengenalan Huruf Hijaiyah Dengan Game Egine Construct

2, dibangun untuk memberikan kemudahan dalam edukasi huruf hijaiyah.

Berdasarkan hasil implementasi dan pembahasan yang telah dilakukan, maka dapat ditarik kesimpulan sebagai berikut.

1. Dengan adanya game ini, dapat membantu siswa/siswi di PAUD Hayatul Ikhlas dalam belajar sekaligus bermain huruf hijaiyah.

2. Membantu guru di PAUD Hayatul Ikhlas dalam memberikan pengalaman belajar sekaligus bermain.

3. Sebagai sarana edukasi yang interaktif dan memberikan pengalaman kepada mahasiswa dalam penelitian game ini.

\section{SARAN}

Sesuai dengan permasalahan yang ada dan setelah perancangan game ini selesai, maka diberikan beberapa saran yang dapat digunakan dalam pengembangan di masa mendatang. Adapun saran yang ingin disampaikan yaitu sebagai berikut.

1. Dikembangkan dengan menggunakan game egine UNITY agar menjadi game yang 3D dan diminati di era globalisasi sekarang.

2. Dikembangkan dengan berbagai tema edukasi seperti huruf latin, Bahasa inggris dan yang laiinya

\section{DAFTAR PUSTAKA}

"Analisis dan Informasi'Ladjamudin, 2005

Abd. Karim Husain, Seni Kaligrafi Khat Naskhi,Tuntunan Menulis Halus Huruf Arab Dengan Metode Komparatif (Jakarta: Pedoman Ilmu Jaya, 1988), hlm. 5

Ahmad Husnain Thohir, Abdul Aziz Nabawi, AlAsas Fi Al-Lughah Al-Arabiyah (Kairo: AlShadru Li Khidmati Al-Thiba'ah,1987), (Anis Farikha, Nadhariyat Al-Lughah (Bairut; Dar AlKuttab Al-Libnani, 1973), hlm. 90)

Blanchard, B. S., \& Fabrycky, W. J.(2006) Systems engineering and analysis (4th ed.) New Jersey: Prentice Hall.

Coad, Peter and Yourdon, Edward. Object-Oriented Design Second Edition, Yourdon Press. 1991.
Cummings, Haag (2006). Mannformation Systems for the Information Age. Toronto, McGraw-Hill Ryerson

Departemen Pendidikan Nasional, Op. Cit., hlm. 401

Egenfeldt-Nielsen, S.Third Generation Educational Use of Computer Games

Fowler, Martin.UML Distiled: Panduan Singkat Bahasa Pemodelan Object Standar, Edisi 3, Penerbit Andi: Yogyakarta. 2004.

Hartono, Jogiyanto. 1999. Analisis Dan Disain Sistem Informasi: pendekatan terstruktur teori dan praktek aplikasi bisnis

http://kbbi.web.id/skripsi (Diakses Tanggal 25 Pebruari 2017)

Muhyiddin, Sekilas Sejarah Tulisan Bahasa Arab, Semprulle, Kediri, 2012, hlm. 3

Nugroho Adi.Rekayasa Perangkat Lunak Berorientasi Objek dengan metode USDP (Unified Software Development Process),Penerbit Andi:Yogyakarta. 2010. 